\title{
Molecular signatures of fossil leaves provide unexpected new evidence for extinct plant relationships
}

\author{
Vivi Vajda ${ }^{1,2 \star}$, Milda Pucetaite ${ }^{3}$, Stephen McLoughlin', Anders Engdahl ${ }^{4}$, Jimmy Heimdal ${ }^{4}$ \\ and Per Uvdal ${ }^{5 \star}$
}

Gene sequences form the primary basis for understanding the relationships among extant plant groups, but genetic data are unavailable from fossils to evaluate the affinities of extinct taxa. Here we show that geothermally resistant fossil cuticles of seed-bearing plants, analysed with Fourier transform infrared (FTIR) spectroscopy and hierarchical cluster analysis (HCA), retain biomolecular suites that consistently distinguish major taxa even after experiencing different diagenetic histories. Our results reveal that similarities between the cuticular biochemical signatures of major plant groups (extant and fossil) are mostly consistent with recent phylogenetic hypotheses based on molecular and morphological data. Our novel chemotaxonomic data also support the hypothesis that the extinct Nilssoniales and Bennettitales are closely allied, but only distantly related to Cycadales. The chemical signature of the cuticle of Czekanowskia (Leptostrobales) is strongly similar to that of Ginkgo leaves and supports a close evolutionary relationship between these groups. Finally, our results also reveal that the extinct putative araucariacean, Allocladus, when analysed through HCA, is grouped closer to Ginkgoales than to conifers. Thus, in the absence of modern relatives yielding molecular information, FTIR spectroscopy provides valuable proxy biochemical data complementing morphological characters to distinguish fossil taxa and to help elucidate extinct plant relationships.

\section{T} he realization that complex biomolecules can survive in the fossil record for millions of years is relatively new and revolutionary. Recent application of state-of-the-art spectroscopic techniques has demonstrated that essentially unaltered biomolecules of soft tissues, for example, collagen and integumentary pigments, can be preserved in animal fossils through deep time $(\leq 190 \text { million years })^{1,2}$. However, recovering the original organic remains from fossil animals with exceptional states of preservation and purifying the corresponding modern reference material is a time-consuming and expensive endeavour. By contrast, the fossil archive of plants offers a vastly greater and more accessible testing ground to investigate the biochemistry of durable tissues. Early studies of the biochemical properties of modern and fossil plants revealed clear chemical differences between the cuticles of various groups ${ }^{3-6}$. These studies provide a firm basis for evaluating whether the biochemistry of plant cuticles preserved over geological timescales can yield taxonomically and phylogenetically useful information.

The majority of solid plant components, for example, cellulose and hemi-cellulose, consist of polysaccharides that undergo extensive alteration (for example, the splitting of long-chain polymers and loss of volatile components), through burial diagenesis over long geological timescales ${ }^{7}$. However, other plant constituents, for example, spores, pollen and leaf cuticles, are among the most resilient organic structures in the geological record and, therefore, are generally abundant and well-preserved. Moreover, these plant components may retain some phylogenetically unique signals, not only in well-preserved fossils, but also in remains with a high level of diagenetic maturity ${ }^{8}$.
The cuticle represents a waxy protective coating over the epidermis of almost all modern vascular plants. The cuticle's chemical resilience results in it being one of the least altered components of fossil leaves experiencing burial and thermal diagenesis. Plant cuticles consist broadly of an insoluble membrane of lipids and hydrocarbon polymers impregnated with soluble waxes resulting in a layer that is relatively impermeable to water and gases ${ }^{9}$. Generally, the cuticle is divided into two major structural constituents: cutin and cutan ${ }^{6}$. Cutin is a lipidic polyester composed principally of hydroxylated and epoxy-hydroxylated $\mathrm{C}_{16^{-}}$and $\mathrm{C}_{18}$-esterified fatty acids. Cutan is a non-ester and non-hydrolyzable matrix incorporating a network of aliphatic compounds linked by ether bonds, which remain after cutin hydrolysis ${ }^{3}$. Additionally, the surface of the cuticle may be covered by various long-chain hydrophobic waxes that serve to protect the plant from desiccation, insect attack and ultraviolet light. These waxes are resilient and may be preserved for long periods in the fossil record-indeed, since the earliest appearance of land plants ${ }^{10}$. The cuticle and its components provide a resource of diagenesis-resistant material that, potentially, can be used to resolve the stratigraphic ranges and relationships of extinct plants.

Deriving biochemical characteristics of organically preserved fossil fragments is important because the identification of fossil plant taxa is traditionally based on morphological characters that are only recognizable in relatively complete macrofossils. Moreover, rich and complex chemotaxonomic data may be extracted and analysed using a range of statistical methods. Over the past three decades, numerous cladistic analyses incorporating morphological and anatomical data from fossils and extant taxa, in some cases

'Department of Palaeobiology, Swedish Museum of Natural History, SE-104 05 Stockholm, Sweden. ${ }^{2}$ Department of Geology, Lund University, SE-223 62 Lund, Sweden. ${ }^{3}$ Department of General Physics and Spectroscopy, Vilnius University, LT-102 57 Vilnius, Lithuania. ${ }^{4}$ MAX-IV laboratory, Lund University, SE-221 00 Lund, Sweden. ${ }^{5}$ Chemical Physics, Department of Chemistry, Lund University, SE-222 41 Lund, Sweden. *e-mail: vivi.vajda@nrm.se; per.uvdal@chemphys.lu.se 
coupled with genomic data from modern plants, have yielded phylogenetic hypotheses that broadly agree for some plant groups but differ markedly for others ${ }^{11-13}$. However, the stratigraphic ranges of plant groups and, consequently, support for the age of clades and the order of tree branching in phylogenetic hypotheses, are poorly resolved because most plant fossils are in the form of minute fragments of robust tissues (cuticles and charcoal) that are difficult to identify using morphological criteria.

Various methods, including pyrolysis-gas chromatography/ mass spectrometry ${ }^{4,8,14}$, nuclear magnetic resonance ${ }^{15}$, Raman spectroscopy $^{16,17}, \mathrm{X}$-ray diffraction ${ }^{18}$, X-ray fluorescence ${ }^{19}$ and X-ray absorption near edge structure (XANES) analysis ${ }^{20}$, have been used to evaluate the chemistry of fossil plants, primarily with the goal of determining whether the organic remains have been substituted by minerals or to understand the diagenetic changes involved in the transition from extant plant tissues or exudates through kerogen to $\mathrm{coal}^{21}$. A major problem in the past has been that molecular identification of ancient plant taxa based on small fossil fragments using traditional geochemical and spectroscopic techniques requires relatively large quantities (approximately $10 \mathrm{mg}$ ) of material for analysis.

Infrared micro-spectroscopy offers an alternative analytical methodology for chemotaxonomy that can be applied even to minute (less than $20 \mu \mathrm{m}$ ) fragments of fossil tissues ${ }^{22,23}$. The method has also been applied to characterize the chemical composition of plant spores and pollen ${ }^{24,25}$ and fossil resins ${ }^{26}$.

Data from infrared spectroscopy of modern plant cuticles, analysed using HCA, have been used successfully to support and clarify the species-level taxonomy of extant plants, for example, in Camellia $^{27}$ and angiosperm pollen ${ }^{28}$. Principal component analysis (PCA) of infrared spectra has also been used to extract variables for systematic (chemotaxonomic) investigations of fossil plants ${ }^{29}$. Such initial studies were based on the association and assignment of functional groups to specific infrared frequencies and intensities from which eight ${ }^{22}$ or fewer ${ }^{23}$ variables were determined. However, when complex biomolecular systems are considered, assignments based on normal modes (the standard approximate description of vibrational motions of, for example, an isolated functional group) are generally a simplification of the commonly coupled and delocalized molecular vibrations expressed in the measured infrared spectra. Therefore, the reduction of a full dataset to a small subset of characters entails a risk, because information necessarily will be lost or misinterpreted.

Here we undertake a FTIR micro-spectroscopic survey of a selection of key fossil and modern gymnospermous plant cuticles (Supplementary Table 1) to assess whether this technique applied together with HCA can yield results (phenetic similarities) that are consistent with current phylogenetic hypotheses. This pilot study uses a range of fossils selected on the basis of their well-resolved taxonomy, ambiguous phylogenetic relationships and/or quality of organic preservation. For some groups, for example, ginkgoaleans and bennettitaleans, multiple taxa from different ages and localities were used to assess whether different diagenetic histories significantly affected the clustering of spectroscopic results in HCA. Importantly and in contrast to previous studies, we chose to use the entire spectral 'fingerprint' region for the analysis of both the fossil and modern leaves, resulting in up to 521 data points in total. We studied extant plant groups with a long fossil record, including araucariacean conifers, Ginkgoales and Cycadales. Where possible, extant and fossil representatives of the same plant families were analysed. The cuticles of several fossil seed-plant taxa with poorly resolved phylogenetic affinities (for example, Bennettitales, Nilssoniales, Ptilozamites, Allocladus and Leptostrobales) were also analysed to assess their biochemical similarities to better-known groups.

\section{Results and discussion}

A selection of extant gymnosperms including the recently discovered 'living fossil', Wollemia nobilis ${ }^{30}$, were initially analysed by FTIR
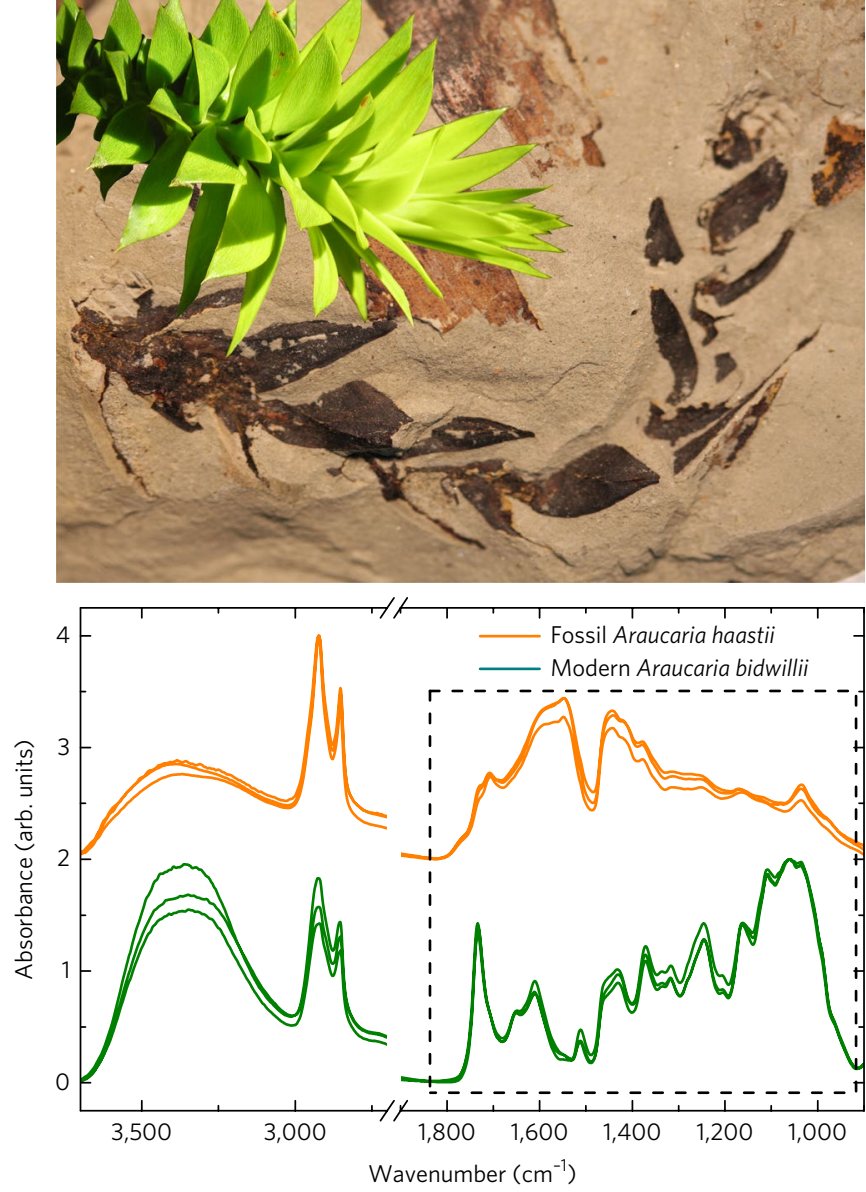

Figure 1 | Morphology and infrared absorption spectra of fossil and modern Araucaria leaves. Top, examples of fossil (Araucaria carinata) and extant (Araucaria bidwillii) Araucariaceae showing the typical variation in leaf morphology within this group. Bottom, infrared absorption spectra of Araucaria haastii (fossil: Late Cretaceous period) and A. bidwillii (extant) recorded at three points on each cuticle sample showing correspondence of some absorption peaks. Note that the fossil cuticle typically contains fewer spectral features, for example, bands are lacking in the region $1,180-900 \mathrm{~cm}^{-1}$ indicating the absence of polysaccharides (cellulose, hemicellulose), but compounds incorporating aliphatic alkene/alkane (bands in the region around 3,000-2,800 $\mathrm{cm}^{-1}$ and 1,470-1,350 $\mathrm{cm}^{-1}$ ) and cyclic molecular structures (bands in the region around 1,600-1,350 $\mathrm{cm}^{-1}$ ) are retained. Note that the spectra have been shifted for clarity.

spectroscopy in order to assess whether the infrared absorption spectra (Figs 1, 2 and Supplementary Fig. 1) contain molecular information (phenetic similarities) that are in accordance with phylogenetic hypotheses based on previous genetic and morphological data. Subsequently, fossil taxa related to the studied extant plants were analysed to determine whether their infrared spectra reveal similar relationships. Finally, we tested a broader range of extinct plant groups to assess their probable affinities based on similarities in their infrared spectra (Fig. 2). For this purpose, the spectra were cluster analysed and presented in the form of dendrograms (Figs 3,4), which express the relative similarities in spectra obtained, respectively, among extant and fossil gymnosperms. We used PCA to further evaluate the relationships between data; these results are illustrated in principal component score plots (Supplementary Figs 2-4).

Extant gymnosperms. The infrared absorption spectra of all modern plants that were analysed contain the same major spectral bands 

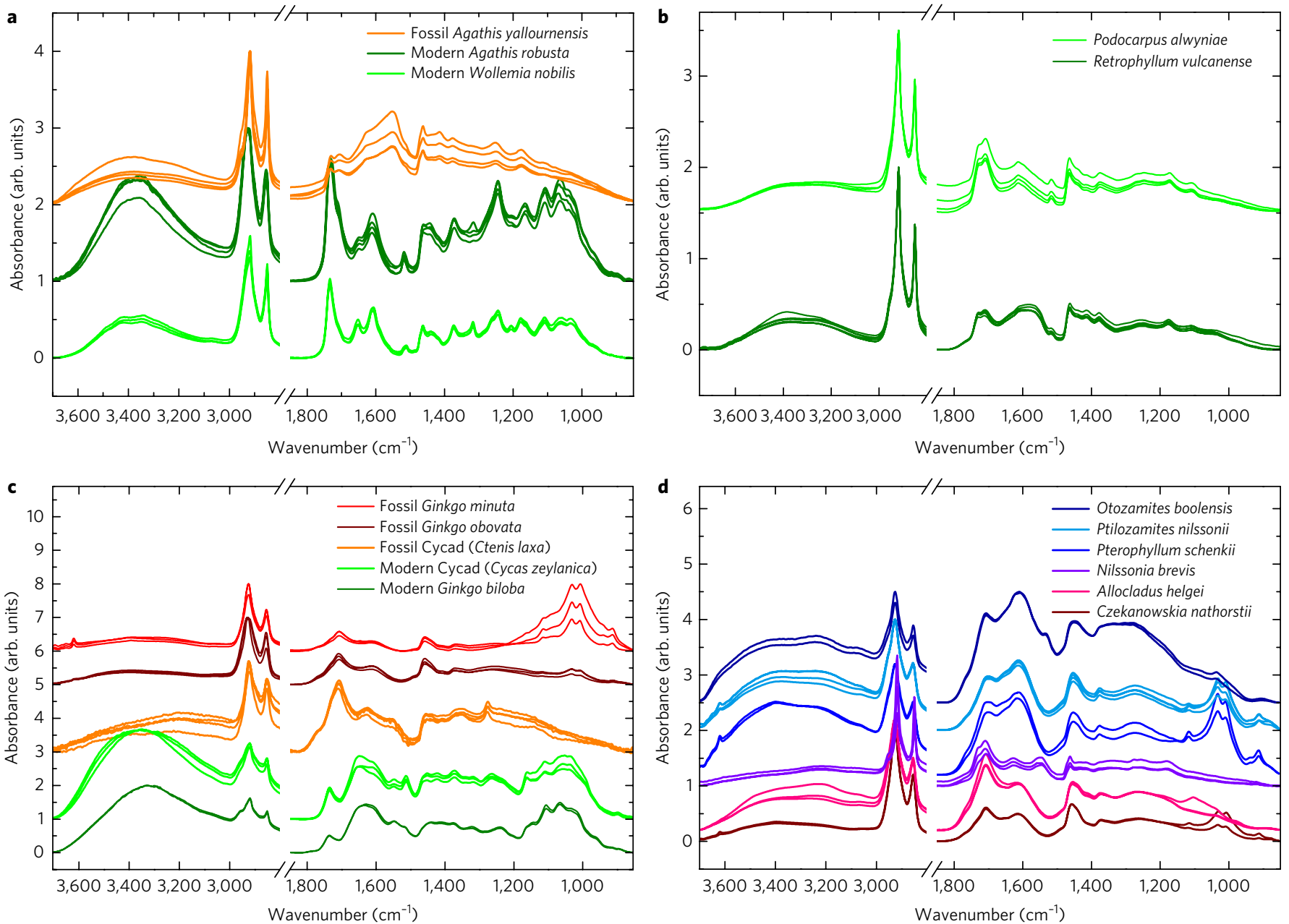

Figure 2 | Infrared absorption spectra of modern and fossil cuticles. a, Modern Agathis robusta, Wollemia nobilis and fossil Agathis yallournensis. b, Fossil Podocarpus alwyniae and Retrophyllum vulcanense. c, Modern Ginkgo biloba and Cycas zeylanica and fossil Ginkgo obovata, Ginkgo minuta and Ctenis laxa. d, Fossil Bennettitales, Leptostrobales, Nilssoniales, Ptilozamites nilssonii and Allocladus helgei. Note the diminished content of water (3,700-3,000 $\left.\mathrm{cm}^{-1}\right)$ and absence of spectral bands assigned to polysaccharides in the spectral region 1,200-970 $\mathrm{cm}^{-1}$ in the spectra of fossil samples. The ester band at $1,734 \mathrm{~cm}^{-1}$ in the spectra of the modern plants is diminished in the spectra of the fossils. Instead, a band at 1,710 $\mathrm{cm}^{-1}$ assigned to carboxylic acid/ketone group is evident. The spectra of G. minuta (c), Czekanowskia nathorstii, Pterophyllum schenkii and Ptilozamites nilssonii (d) contain spectral bands of mineral kaolinite: at 3,620, 3,653, 3,670, 3,698, 1,115, 1,034, 1,008 and $913 \mathrm{~cm}^{-1}$. Note that the spectra have been shifted for clarity.

reflecting shared dominant compounds: for example, polysaccharides, cutin and lipids. Ginkgo biloba and Cycas zeylanica, however, yield additional spectral features, mostly evident in the spectral region $1,650-1,500 \mathrm{~cm}^{-1}(\mathrm{C}-\mathrm{N}, \mathrm{C}=\mathrm{C}$ vibrations) where spectral bands are more intense, much broader and with shifted peak positions (Figs 1, 2a,c). This indicates that these plants have additional compounds and/or different polymer structures from those that typically give rise to spectral bands in this region. In addition, lipid content (represented by the spectral band at $1,734 \mathrm{~cm}^{-1}$ and assigned to a $\mathrm{C}=\mathrm{O}$ stretching vibration) appears to be lower in Ginkgo and Cycas than in other groups. These characters segregate Ginkgo and Cycas from the remaining gymnosperms, as reflected both in the dendrogram (Fig. 3) and in the PCA score plots (Supplementary Figs 2, 3). The more subtle differences in the spectra of the other seed plants made it necessary to use cluster analysis to separate them into groups (see Methods).

The clustering of taxa based on the infrared spectra (chemophenetic similarity) is generally consistent with the inferred phylogenetic relationships of extant seed plants based on molecular and morphological evidence ${ }^{11-13}$. The only deviation from this pattern is that Ginkgo is resolved with closer affinities to cycads than to conifers (Figs 3, 4 and Supplementary Figs 2-4). Significantly, the relationships within the Araucariaceae (Araucaria, Agathis and Wollemia) expressed in the dendrograms (Fig. 3 and Supplementary Fig. 2) are broadly consistent with recent phylogenic hypotheses in which Wollemia is resolved as sister to Agathis and these in turn being sister to Araucaria ${ }^{31}$, although the greater similarities of Araucarcia heterophylla with both Wollemia and Agathis than with other Araucaria species in our results is unexpected.

Fossil gymnosperms. The infrared absorption spectra of the fossil samples generally contain fewer features than the spectra of the extant plants (Figs 1,2). This reflects the substantially reduced diversity of chemical compounds, which is a result of diagenesis and is consistent with previous observations for ginkgoaleans ${ }^{5}$. For example, the absence of bands in the region of $1,180-900 \mathrm{~cm}^{-1}$ indicates that there are no or only small quantities of polysaccharides (cellulose, hemicellulose) remaining in the fossil cuticles (Figs 1,2). Nevertheless, we recognize compounds containing cyclic molecular structures (expressed by bands in the spectral region around $1,600 \mathrm{~cm}^{-1}$ ) both in modern and in fossil plants. The molecular structures are modified in the fossils as indicated by shifts and changing shapes of the spectral bands. 

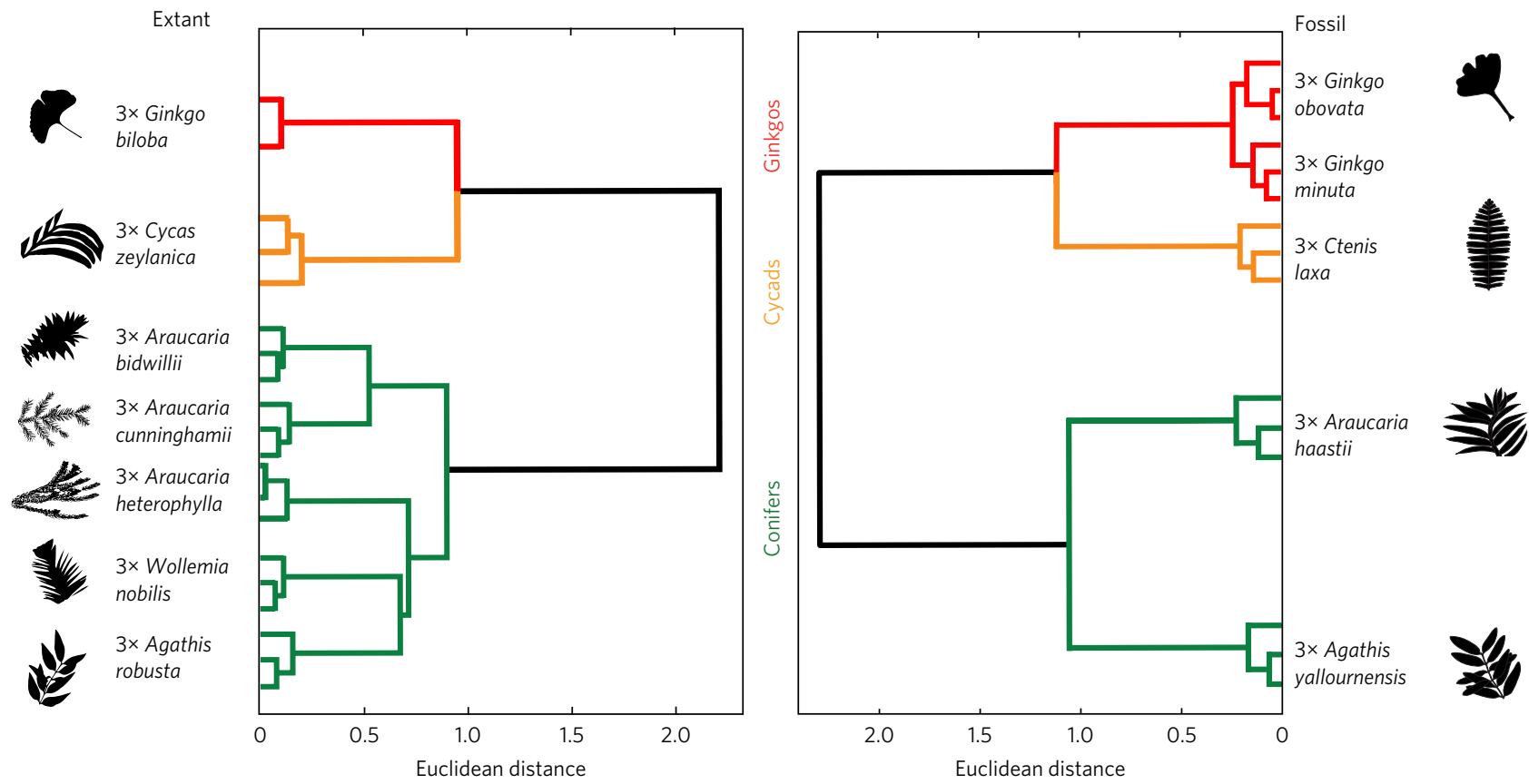

Figure 3 | Dendrograms based on HCA of infrared absorption spectra of the cuticles from extant and related fossil gymnosperms. The dendrograms reveal that samples yield spectral signatures that can differentiate individual species, and that the relationships between major groups of fossil plants (right) match those for related extant (left) species. This is consistent with the results shown in the PCA score plots of extant and fossil plants (Supplementary Figs 2, 3). In most cases, three points were analysed per cuticle sheet for infrared spectral analysis.

The use of pyrolysis-gas chromatography/mass spectroscopy and FTIR micro-spectroscopy as described in refs ${ }^{4,5}$, revealed aliphatic (alkene/alkane) and cyclic (aromatic, phenolic) compounds preserved in the cuticles of fossil Ginkgo and fossil conifers. Our results of infrared spectral analysis of both modern and fossil cuticles (refer to Supplementary Information for detailed spectral analysis) confirm these observations for these and other fossil groups. The relative amounts of the compounds (as reflected by different intensities of the spectral bands originating from different compounds) differ, but are specific to a certain taxon, thereby forming the molecular basis for grouping the taxa phenetically.

Cluster analysis was applied to the spectra of the fossil gymnosperms in the same manner as for the modern plants. As for cuticles of extant taxa, two major groups are differentiated in the dendrogram of fossil gymnosperms based on infrared absorption spectra (Fig. 3); one grouping containing all conifers, the other linking ginkgoaleans and cycads.

Although derived from widely separated localities (Supplementary Table 1), with ages ranging from the Triassic period (205 million years ago: Ginkgo obovata and G. minuta) to Miocene epoch (20 million years ago: Agathis yallournensis), and coalification rank ranging from lignite B (A. yallournensis) to high volatile $\mathrm{C}$ bituminous (Ctenis laxa), the dendrogram of the fossil gymnosperms reveals a pattern matching that of their extant relatives. Ideally, long temporal series of multiple species and fossils from each clade subject to differing thermal maturities and diagenetic histories are needed to verify the consistency of spectral signatures within each ancient plant group. Nevertheless, our survey of spectral signatures from diverse higher taxa, some represented by several species and derived from widely separated localities and strata of different thermal ranks provides promising results indicative of relative consistency in the infrared spectra of taxa. Despite the range of chemical changes that occur to plant matter during coalification diagenesis, the major organic components of leaf cuticle clearly retain a molecular signature of their botanical group.
Ginkgoales, Bennettitales and fossil gymnosperms of uncertain affinity. Given that fossil Cycadales, Ginkgoales and conifers have similar chemo-phenetic characters to their extant relatives (based on their cuticular FTIR absorption spectra as expressed in the dendrograms), leaf cuticles from several extinct gymnosperms with ambiguous phylogenetic relationships were analysed, together with a broader range of fossils related to extant seed plants, to assess potential chemotaxonomic signals (Fig. 4). Samples from 13 fossil gymnosperm taxa were included in this analysis. Some of the fossil groups, for example, Czekanowskia and Ptilozamites, known only from Mesozoic continental strata of the Northern Hemisphere, have not been included in past phylogenetic analyses owing to insufficient available characters from their foliar architecture or lack of associated reproductive structures. Moreover, Nilssoniales, as represented by the composite association of Nilssonia, Androstrobus and Beania (NILANBE) in a previous phylogenetic analysis ${ }^{32}$, may not represent a natural affiliation of organs, since these fossils have not been found attached. Rather, the vegetative organs of Nilssonia and the morphologically similar Nilssoniocladus have architectures (for example, long-shoot and short-shoot complexes) that differ greatly from typical cycads. We argue that Nilssoniales are markedly different from cycads on a morphological basis and should be treated as an independent group whose reproductive structures have not been verified. Our cluster analysis of the recorded spectra (Methods and Fig. 2) shows that the fossil species fall into unique subclusters indicating consistency of the analytical procedure for separating individual taxa (that is, the spectra are taxon-specific).

Two major groupings emerge in the dendrogram of infrared spectra (Fig. 4). One branch unites podocarpacean and araucariacean conifers (excluding the Jurassic Allocladus) with respect to other gymnosperms. This relationship uniting conifers is consistent with all modern phylogenetic analyses of gymnosperms ${ }^{33}$.

The second major branch unites a broad range of gymnosperms, some of which have poorly resolved phylogenetic affinities. Within this branch, Bennettitales (Otozamites and Pterophyllum) form a well-defined group in association with Ptilozamites and Nilssoniales 


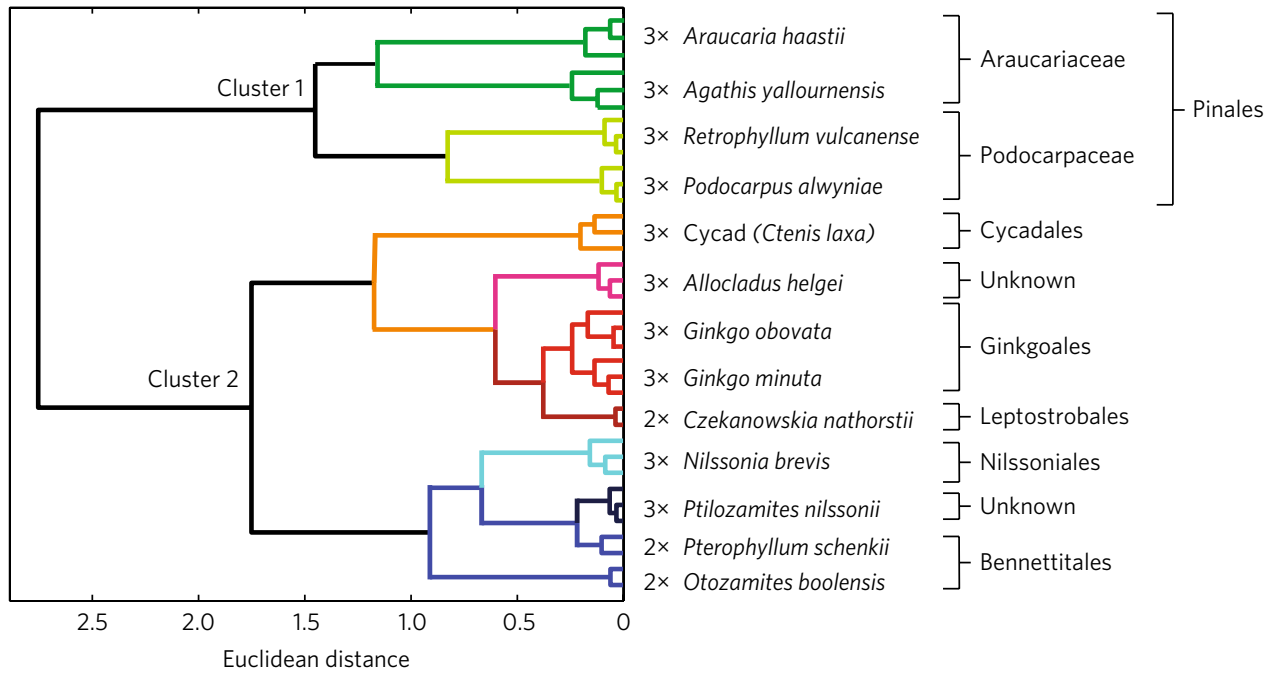

Figure 4 | Dendrogram based on HCA of infrared absorption spectra of an expanded group of 13 fossil gymnosperm taxa. The dendrogram shows araucariacean and podocarpacean conifers as a cohesive (Pinales) group (cluster 1). Cycads, ginkgoaleans and a range of extinct gymnosperm orders are aggregated in a less well resolved group (cluster 2). Notably, cycads, Ginkgo, Leptostrobales and the enigmatic gymnosperm Allocladus group in one subcluster, whereas Bennettitales are closely linked with Nilssoniales and Ptilozamites in a second well-resolved subcluster. This is consistent with the results shown in the PCA score plots of fossil plants (Supplementary Fig. 4).

(two gymnosperms with bennettite-like leaves but no known reproductive organs in organic connection). This cluster is in turn linked to a group incorporating Cycadales on one sub-branch, and Leptostrobales, Ginkgoales and the putative araucariacean Jurassic conifer Allocladus on a second sub-branch.

Early palaeobotanical studies generally linked Bennettitales to Cycadales based on broad similarities in leaf form and growth habit ${ }^{34}$. However, more recent anatomical studies ${ }^{35}$ and cladistic analyses ${ }^{11,12}$, particularly emphasizing reproductive and stomatal differences, have indicated that Bennettitales are not closely related to Cycadales. Nilssoniales (incorporating Nilssonia and Nilssoniocladus and associated reproductive structures) have been treated variably as a paraphyletic grade within Cycadales ${ }^{32}$, as a major monophyletic group nested within Cycadales ${ }^{36}$, or as a separate order of seed plants ${ }^{37}$. The enigmatic Ptilozamites has been excluded from past phylogenetic studies of seed plants, because insufficient characters are available to include in the analyses ${ }^{38}$. The genus has short leaflets with bennettite-like venation but, in contrast to Bennettitales, the leaves are bipinnate with cyclocytic stomata ${ }^{38}$. The relationships between these groups remain ambiguous and will only be clarified when wholeplant reconstructions based on attached reproductive and vegetative organs become available and the phylogenetic importance of key morphological character states are resolved. Superficial similarities in foliar morphology may represent convergence and, importantly, might sustain erroneous palaeoenvironmental interpretations. For example, Cycadales, both extant and extinct, are largely confined to tropical and subtropical (palaeo)climates, whereas Bennettitales, Nilssoniales and Ptilozamites with equivalent gross leaf architecture occupied much broader palaeoclimatic ranges, extending into near polar latitudes in the Mesozoic era ${ }^{39}$. Our cluster analysis of infrared spectra of cuticles shows that Bennettitales and Cycadales are widely separated. By contrast, Bennettitales, Nilssoniales and Ptilozamites are grouped closely (Fig. 4) and this is corroborated by PCA score plots based on infrared absorption spectra (Supplementary Fig. 4). This might indicate a close phylogenetic relationship between these groups or retention of shared ancestral biochemical characters.

Czekanowskia (Leptostrobales) is grouped closer to Ginkgoales than to Cycadales (Fig. 4). This phenetic similarity is consistent with traditional systematic placements of Leptostrobales based on leaf morphology, epidermal anatomy and shoot architecture ${ }^{40}$, which are similar to those of Ginkgo. The relatively strong spectral similarities between Cycadales and Leptostrobales together with Ginkgoales (see dendrogram in Fig. 4) is noteworthy, because Cycadales are usually recovered as basal amongst extant gymnosperms in phylogenies of major seed-plant groups based on morphological data, whereas Ginkgoaleans are more derived, sharing some wood, shoot architecture and reproductive characters with conifers ${ }^{11}$. It is possible that the similarities between Cycadales and Ginkgoales together with Leptostrobales in our analysis reflect symplesiomorphic (shared ancestral) characters and may relate to an absence of cutan, which has a distinctive spectral signal in other gymnosperms ${ }^{17}$. Cycadales and Ginkgoales clearly share various other archaic traits, such as motile sperm and asaccate sulcate pollen ${ }^{12}$. However, it is noteworthy that a Cycadales and Ginkgoales clade has been recovered repeatedly in some recent phylogenetic analyses of seed plants using nuclear $18 \mathrm{~S}$ ribosomal (r)RNA sequences ${ }^{41}$, chloroplast genes ${ }^{42}$, amino acids ${ }^{43}$ and in transcriptome analyses of land plants ${ }^{44}$.

Unexpectedly, our analysis also shows that the chemistry of Allocladus cuticle is most similar to that of plants in cluster 2 and not the conifers in cluster 1 (Fig. 4). Allocladus has been allied tentatively with araucariacean conifers (cluster 1) based on cuticular morphology ${ }^{45}$. However, its leaves are unusual among araucariaceans in having toothed margins. Moreover, reproductive structures abundantly co-preserved with Allocladus helgei from the Jurassic period of Australia ${ }^{45}$ have been assigned to an extinct group of seed-ferns (Knezourocarponaceae/Palissyaceae) ${ }^{46}$, suggesting that Allocladus may not be coniferous. Cuticular chemistry may thus be of value in providing additional characters for resolving the systematic affinities of various extinct plant groups, such as Allocladus, once infrared absorption spectra or other biochemical data from sufficient taxa are incorporated into the data matrix.

\section{Conclusions}

This pilot study, by necessity and space limitation, uses only reconnaissance sampling of the major plant groups and a limited dataset. Nevertheless, the results hold promise that FTIR spectroscopy may be a useful technique, usable on even minute cuticular remains, for discriminating fossil plant taxa and for providing informative 
characters for phylogenetic studies. Our results reveal that consistent chemical signatures specific for each fossil taxon are present in cuticles and can be obtained by FTIR spectroscopy. Although some organic compounds in the fossil leaves have polymerized and changed in other ways through diagenetic alteration, sufficient molecular content is preserved in key regions to reflect the plants' original chemical signatures. Notably, we show that HCA clustering of FTIR data from fossil and equivalent modern taxa yields groupings that are generally consistent with the phylogenetic relationships that have been inferred for extant and extinct seed plants (based on both molecular and morphological evidence).

Notably, our results present some new perspectives on the affinity of several enigmatic fossil gymnosperms with ambiguous phylogenetic relationships. For example, our results suggest that the extinct Nilssoniales and Ptilozamites are closely allied with Bennettitales rather than with Cycadales or pteridosperms-their traditional placements. A close relationship between Ginkgoales and the extinct Leptostrobales is also supported by FTIR spectral similarities of fossil cuticle. Furthermore, the systematic position of Allocladus within Araucariaceae should be reassessed based on its close association with Ginkgo in the cluster analysis of infrared spectra. These results indicate that FTIR spectroscopy can detect shared biochemical signatures between modern and fossil cuticles and has the potential to supplement morphological and molecular data in discriminating and relating extant and fossil taxa. It is important that FTIR spectral data from additional fossil taxa are incorporated into morphology-based phylogenetic analyses in future in order to clarify the evolutionary relationships of the large number of extinct plant groups of presently unresolved affinities.

To further test the utility of this FTIR technique for identifying shared molecular signatures of plant groups, it should be applied in future to an expanded range of extant and fossil taxa across the plant kingdom. It should also be applied to individual fossil species preserved in long time series with fossil examples having experienced the full range of thermal and diagenetic histories to evaluate the limitations of the technique.

\section{Methods}

Materials. Modern and fossil leaves from related genera across a broad range of gymnosperm groups were sampled for cuticle. The fossils derive from strata of various ages and geographical sites held in the collections of the Swedish Museum of Natural History, Stockholm, the Natural History Museum of Denmark, Copenhagen, and the Queensland Herbarium, Mt Coot-tha, Brisbane (Supplementary Table 1). Cuticles of extant taxa were recovered from plants growing in the Botanical Garden of Lund University. Cuticles of extant taxa were peeled directly from the leaf surface without chemical processing, then dried in a vacuum chamber before FTIR analysis. Fossil leaves were processed with Schulze's reagent $\left(\mathrm{HNO}_{3}+\mathrm{HClO}_{3}\right)$ at $50{ }^{\circ} \mathrm{C}$ between five minutes and six hours to remove coalified mesophyll tissues; the recovered cuticle was rinsed in distilled water then air-dried.

Experimental methods. Infrared micro-spectroscopy was performed at beamline D7 at the MAX-IV laboratory, Lund University, Lund, Sweden. A Hyperion 3000 infrared microscope combined with FTIR spectrometer IFS 66v/S (Bruker Optik $\mathrm{GmbH}$, Ettlingen, Germany) with globar light source and $\mathrm{KBr}$ beamsplitter was used for the measurements. The microscope is equipped with a single element liquid-nitrogen-cooled MCT detector. A $15 \times / 0.4$ objective was used. The size of a knife-edge aperture was varied according to the size of the sample when collecting the spectra in order to exclude stray light (radiation that did not propagate through the sample) reaching the detector. One hundred and twenty-eight interferograms were averaged and the result Fourier-transformed into a spectrum applying the Blackmann-Harris 3 apodization function and zero filling factor 2 . A $4 \mathrm{~cm}^{-1}$ spectral resolution was used. Spectra in the range $4,000-850 \mathrm{~cm}^{-1}$ were recorded. The lower wavenumber limit is determined by the use of the $\mathrm{CaF}_{2}$ optical window.

At least three separate cuticles of each taxon were analysed and several spectra were recorded in multiple locations on each cuticle sample. Algorithms of atmospheric compensation and baseline correction (rubber-band method) were applied to three selected spectra of high quality (no saturated absorptions, high signal-to-noise ratio, no significant baseline oscillations) in accordance with spectral pre-processing as previously described ${ }^{47}$. The algorithms are default functions of the OPUS software (Bruker Optik GmbH, Ettlingen, Germany).
Subsequently, the spectra were analysed using the MATLAB package (version 7.14, MathWorks, Inc., USA) as it allows better control of the processing.

Data analysis. Spectral datasets obtained by FTIR microspectroscopy were evaluated by HCA and PCA performed on vector-normalized, first-derivative (calculated by the Savitzky-Golay algorithm using a polynomial of degree two and window size of nine points) spectra. Euclidean distances $\left(d\left(s_{1}, s_{2}\right)=\sqrt{\sum_{i=1}^{n}\left(s_{1 i}-s_{2 i}\right)^{2}}\right.$ where $s_{1}, s_{2}$ are spectra between which the Euclidean distance is calculated and $s_{1 i}, s_{2 i}$ are spectral data points in the corresponding spectrum) between the spectra were calculated, then Ward's algorithm was used to group the data. Different spectral areas, namely, $3,800-850 \mathrm{~cm}^{-1}, 3,800-1,850 \mathrm{~cm}^{-1}$ and $1,850-850 \mathrm{~cm}^{-1}$, were at first used for the clustering. For fossil samples, the limits of the spectral regions were shifted to $3,100-1,300 \mathrm{~cm}^{-1}, 3,100-1,850 \mathrm{~cm}^{-1}$ and $1,850-1,300 \mathrm{~cm}^{-1}$ in order to exclude spectral bands of the mineral kaolinite ${ }^{48}$. The 'fingerprint' (approximately 1,850-1,300 $\mathrm{cm}^{-1}$ ) region contains the most information on the molecular content of the samples ${ }^{49}$; accordingly, the high-energy region was removed from further analysis. The results were displayed in the form of dendrograms in which the heterogeneity factor-Euclidean distance-represents proximity between the clusters. An algorithm of optimal leaf ordering ${ }^{50}$ was applied for the adjacent clusters to have the highest similarity.

In order to test how taxon sampling affects the analysis, various datasets incorporating different taxa were compiled. As an example for modern plants, the cohesion of Araucariaceae (the ingroup) was tested against the spectral signals of all other species (the outgroup), by varying the representation of outgroup taxa. The effect of the sampling within the ingroup was tested by composing datasets with reduced numbers of araucariacean species. The re-sampling was replicated at least 10 times.

Finally, in order to test how the choice of the wavenumber regions affects the analysis, 100 sets of samples were composed containing only $50 \%$ of randomly selected variables (jackknifing). In order to maintain the resolution of the original data, intervals between the randomly selected data points were interpolated. The reduction in the size of the original dataset had no or minimal influence with respect to the original dataset demonstrating the stability of the analysis.

Code availability. The MATLAB code that was used for HCA and PCA analysis is available upon request from the authors.

Data availability. The data that support the findings of this study are available from the authors upon request.

Received: 3 February 2017; Accepted: 24 May 2017; Published online: 3 July 2017

\section{References}

1. Lindgren, J. et al. Molecular preservation of the pigment melanin in fossil melanosomes. Nat. Commun. 3, 824 (2012).

2. Lindgren, J. et al. Skin pigmentation provides evidence of convergent melanism in extinct marine reptiles. Nature 506, 484-488 (2014).

3. van Bergen, P. F. et al. Resistant biomacromolecules in the fossil record. Acta Bot. Neerl. 44, 319-342 (1995).

4. Mösle, B., Finch, P., Collinson, M. E. \& Scott, A. C. Comparison of modern and fossil plant cuticles by selective chemical extraction monitored by flash pyrolysis-gas chromatography-mass spectrometry and electron microscopy. J. Anal. Appl. Pyrol. 40-41, 585-597 (1997).

5. Mösle, B. et al. Factors influencing the preservation of plant cuticles: a comparison of morphology and chemical composition of modern and fossil examples. Org. Geochem. 29, 1369-1380 (1998).

6. Gupta, N. S., Collinson, M. E., Briggs, D. E. G., Evershed, R. P. \& Pancost, R. D. Reinvestigation of the occurrence of cutan in plants: implications for the leaf fossil record. Paleobiol. 32, 432-449 (2006).

7. de Leeuw, J. W., Versteegh, G. J. M. \& van Bergen, P. F. Biomacromolecules of algae and plants and their fossil analogues. Plant Ecol. 182, 209-233 (2006).

8. Amijaya, H., Schwarzbauer, J. \& Littke, R. Organic geochemistry of the Lower Suban coal seam, South Sumatra Basin, Indonesia: palaeoecological and thermal metamorphism implications. Org. Geochem. 37, 261-279 (2006)

9. Lara, I., Belge, B. \& Goulao, L. F. A focus on the biosynthesis and composition of cuticle in fruits. J. Agric. Food Chem. 63, 4005-4019 (2015).

10. Versteegh, G. J. M. \& Riboulleau, A. An organic geochemical perspective on terrestrialization. Geol. Soc. Spec. Publ. 339, 11-36 (2010).

11. Crane, P. R. Phylogenetic analysis of seed plants and the origin of angiosperms. Ann. Mo. Bot. Gard. 72, 716-793 (1985).

12. Hilton, J. \& Bateman, R. M. Pteridosperms are the backbone of seed-plant phylogeny. J. Torrey Bot. Soc. 133, 119-168 (2006)

13. Doyle, J. A. Seed ferns and the origin of angiosperms. J. Torrey Bot. Soc. 133, 169-209 (2006).

14. Briggs, D. E. G. Molecular taphonomy of animal and plant cuticles: selective preservation and diagenesis. Phil. Trans. R. Soc. Lond. B 354, 7-17 (1999). 
15. Hatcher, P. G., Wilson, M. A., Vassallo, A. M. \& Lerch, H. E. III. Studies of angiospermous wood in Australian brown coal by nuclear magnetic resonance and analytical pyrolysis: new insights into the early coalification process. Int. J. Coal Geol. 13, 99-126 (1989).

16. Qu, Y., Engdahl, A., Zhu, S., Vajda, V. \& McLoughlin, N. Ultrastructural heterogeneity of carbonaceous material in ancient cherts: investigating biosignature origin and preservation. Astrobiology 15, 825-842 (2015).

17. Heredia-Guerrero, J. A. et al. Infrared and Raman spectroscopic features of plant cuticles: a review. Front. Plant Sci. 5, 305 (2014).

18. Alencar, W. J. et al. Spectroscopic analysis and X-ray diffraction of trunk fossils from the Parnaíba Basin, northeast Brazil. Spectrochim. Acta A Mol. Biomol. Spectrosc 135, 1052-1058 (2014).

19. Bomfleur, B., McLoughlin, S. \& Vajda, V. Fossilized nuclei and chromosomes reveal 180 million years of genomic stasis in royal ferns. Science 343, 1376-1377 (2014).

20. Boyce, C. K. et al. Organic chemical differentiation within fossil plant cell walls detected with X-ray spectromicroscopy. Geology 30, 1039-1042 (2002).

21. D’Angelo, J. A., Zodrow, E. L. \& Camargo, A. Chemometric study of functional groups in Pennsylvanian gymnosperm plant organs (Sydney Coalfield, Canada): implications for chemotaxonomy and assessment of kerogen formation. Org. Geochem. 41, 1312-1325 (2010).

22. D'Angelo, J. A. \& Zodrow, E. L. Chemometric study of functional groups in different layers of Trigonocarpus grandis ovules (Pennsylvanian seed fern, Canada). Org. Geochem. 42, 1039-1054 (2011).

23. D'Angelo, J. A. \& Zodrow, E. L. Chemometric study of structural groups in medullosalean foliage (Carboniferous, fossil Lagerstätte, Canada): chemotaxonomic implications. Int. J. Coal Geol. 138, 42-54 (2015).

24. Lomax, B. H. et al. A novel palaeoaltimetry proxy based on spore and pollen wall chemistry. Earth Planet. Sci. Lett. 353-354, 22-28 (2012).

25. Steemans, P., Lepot, K., Marshall, C. P., Le Hérissé, A. \& Javaux, E. J. FTIR characterisation of the chemical composition of Silurian miospores (cryptospores and trilete spores) from Gotland, Sweden. Rev. Palaeobot. Palynol. 162, 577-590 (2010).

26. Seyfullah, L. J., Sadowski, E.-M. \& Schmidt, A. Species-level determination of closely related araucarian resins using FTIR spectroscopy and its implications for the provenance of New Zealand amber. Peer J. 3, e1067 (2015).

27. Lu, H.-F., Shen, J.-B., Lin, X.-Y. \& Fu, J.-L. Relevance of fourier transform infrared spectroscopy and leaf anatomy for species classification in Camellia (Theaceae). Taxon 57, 1274-1288 (2008).

28. Zimmermann, B. \& Kohler, A. Infrared spectroscopy of pollen identifies plant species and genus as well as environmental conditions. PLOS ONE 9 , e95417 (2014)

29. Niklas, K. J. \& Gensel, P. G. Chemotaxonomy of some Paleozoic vascular plants. Part II: chemical characterization of major plant groups. Brittonia 29, 100-111 (1977).

30. Jones, W. G., Hill, K. D. \& Allen, J. M. Wollemia nobilis, a new living Australian genus and species in the Araucariaceae. Telopea (Syd.) 6, 173-176 (1995).

31. Escapa, I. H. \& Catalano, S. A. Phylogenetic analysis of Araucariaceae: integrating molecules, morphology, and fossils. Int. J. Plant Sci. 174 1153-1170 (2013)

32. Hermsen, E. J., Taylor, T. N., Taylor, E. L. \& Stevenson, D. W. Cataphylls of the Middle Triassic cycad Antarcticycas schopfii and new insights into cycad evolution. Am. J. Bot. 93, 724-738 (2006).

33. Chaw, S.-M., Parkinson, C. L., Cheng, Y., Vincent, T. M. \& Palmer, J. D. Seed plant phylogeny inferred from all three plant genomes: monophyly of extant gymnosperms and origin of Gnetales from conifers. Proc. Natl Acad. Sci. USA 97, 4086-4091 (2000).

34. Morris, J. Remarks upon the recent and fossil cycadaceae. Ann. Mag. Nat. Hist. 7, 110-120 (1841).

35. Delevoryas, T. Investigations of North American cycadeoids: cones of cycadeoidea. Am. J. Bot. 50, 45-52 (1963).

36. Kimura, T. \& Sekido, S. Nilssoniocladus n. gen. (Nilssoniaceae, n. fam.), newly found from the early Lower Cretaceous of Japan. Palaeontographica B 153, 111-118 (1975).

37. Pott, C., McLoughlin, S., Lindström, A., Wu, S.-Q. \& Friis, E. M. Baikalophyllum lobatum and Rehezamites anisolobus: two seed plants with "cycadophyte" foliage from the Early Cretaceous of Eastern Asia. Int. J. Plant Sci. 173, 192-208 (2012).
38. Kustatscher, E. \& van Konijenburg-van Cittert, J. H. A. Taxonomical and palaeogeographic considerations on the seedfern genus Ptilozamites with some comments on Anomozamites, Dicroidium, Pseudoctenis and Ctenozamites. Neues Jahrb. Geol. Paläontol. Abh. 243, 71-100 (2007).

39. Rees, P. M., Ziegler, A. M. \& Valdes, P. J. Warm Climates in Earth History (eds Huber, B. T., Macleod, K. G. \& Wing, S. L.) (Cambridge Univ. Press, 2000).

40. Liu, X.-Q., Li, C.-S. \& Wang, Y.-F. Plants of Leptostrobus Heer (Czekanowskiales) from the Early Cretaceous and Late Triassic of China, with discussion of the genus. J. Integr. Plant Biol. 48, 137-147 (2006).

41. Chaw, S. M., Zharkikh, A., Sung, H. M., Lau, T. C. \& Li, W. H. Molecular phylogeny of extant gymnosperms and seed plant evolution: analysis of nuclear 18S rRNA sequences. Mol. Biol. Evol. 14, 56-68 (1997).

42. Ruhfel, B. R., Gitzendanner, M. A., Soltis, P. S., Soltis, D. E. \& Burleigh, J. G. From algae to angiosperms-inferring the phylogeny of green plants (Viridiplantae) from 360 plastid genomes. BMC Evol. Biol. 14, 23 (2014).

43. Wu, C.-S., Chaw, S.-M. \& Huang, Y.-Y. Chloroplast phylogenomics indicates that Ginkgo biloba is sister to cycads. Genome Biol. Evol. 5, 243-254 (2013).

44. Wickett, N. J. et al. Phylotranscriptomic analysis of the origin and early diversification of land plants. Proc. Natl Acad. Sci. USA 111, E4859-E4868 (2014)

45. Jansson, I.-M., McLoughlin, S., Vajda, V. \& Pole, M. An Early Jurassic flora from the Clarence-Moreton Basin, Australia. Rev. Palaeobot. Palynol. 150, 5-21 (2008).

46. Pattemore, G. A., Rigby, J. F. \& Playford, G. Palissya: a global review and reassessment of eastern Gondwanan material. Rev. Palaeobot. Palynol. 210, 50-61 (2014).

47. Baker, M. J. et al. Using fourier transform IR spectroscopy to analyze biological materials. Nat. Protoc. 9, 1771-1791 (2014).

48. Madejová, J. \& Komadel, P. Baseline studies of the clay minerals society source clays: infrared methods. Clays Clay Miner. 49, 410-432 (2001).

49. Domenighini, A. \& Giordano, M. Fourier transform infrared spectroscopy of microalgae as a novel tool for biodiversity studies, species identification, and the assessment of water quality. J. Phycol. 45, 522-531 (2009).

50. Bar-Joseph, Z., Gifford, D. K. \& Jaakkola, T. S. Fast optimal leaf ordering for hierarchical clustering. Bioinformatics 17, S22-S29 (2001).

\section{Acknowledgements}

This research was financially supported by grants from Lund University, faculty funding for synchrotron-light-related projects for ESS and MAX IV to V.V., the Swedish Research Council (VR grant 2015-4264 to V.V., and VR grant 2014-5234 to S.M.), This research was further funded by the Swedish Research Council (VR) under grant LUCCI (Lund University Carbon Cycle Centre) and the Utrecht Network Young researchers' grant to M.P. We thank the Botanical Garden of Lund University, Sweden for giving permission to sample plant leaves; M. Pole (Nanjing Institute of Geology and Paleontology, Nanjing, China) for providing fossil cuticles from New Zealand and Svend Visby Funder (Centre for GeoGenetics, Natural History Museum, Copenhagen, Denmark) for giving access to T. M. Harris' fossil collections.

\section{Author contributions}

V.V. and P.U. conceived and led the project, V.V. and S.M. recovered and prepared fossil cuticles, V.V. collected the modern cuticles. M.P., V.V. and A.E. carried out FTIR spectroscopy measurements, A.E., P.U. and J.H. provided expertise in infrared spectroscopy. Spectral analysis was performed by M.P., P.U. and J.H.S. All authors contributed to writing the paper.

\section{Competing interests}

The authors declare no competing financial interests.

\section{Additional information}

Supplementary information is available for this paper at doi:10.1038/s41559-017-0224-5.

Reprints and permissions information is available at www.nature.com/reprints.

Correspondence and requests for materials should be addressed to V.V. and P.U.

Publisher's note: Springer Nature remains neutral with regard to jurisdictional claims in published maps and institutional affiliations. 
In the format provided by the authors and unedited.

\section{Molecular signatures of fossil leaves provide unexpected new evidence for extinct plant relationships}

Vivi Vajda ${ }^{1 \star}$, Milda Pucetaite $^{2}$, Stephen McLoughlin ${ }^{1}$, Anders Engdahl $^{3}$, Jimmy Heimdal ${ }^{3}$ and Per Uvdal $\left.\right|^{3,4 \star}$

'Department of Palaeobiology, Swedish Museum of Natural History, Stockholm, Sweden. ${ }^{2}$ Department of General Physics and Spectroscopy, Vilnius University, Vilnius, Lithuania. ${ }^{3}$ MAX-IV laboratory, Lund University, Lund, Sweden. ${ }^{4}$ Chemical Physics, Department of Chemistry, Lund University, Lund, Sweden.

*e-mail:vivi.vajda@nrm.se; per.uvdal@chemphys.lu.se 
Supplementary Table 1. List of fossil and modern plant cuticles analysed by means of FTIR spectroscopy in this study. Each taxon is followed by the locality where the fossil was found, geological epoch and approximate age in million years of the sediments hosting the fossil cuticle according to Pole 1997' ; Cookson \& Duigan $1951^{2}$, Bose $1975^{3}$, McLoughlin et al. 2002 ${ }^{4}$, Jansson et al. 20085, 5 , Lundblad $1950^{8}$, Harris $1932^{9}$, Harris $1935^{10}$. The fossils range in coalification rank from lignite B (Agathis yallournensis: Miocene of the Gippsland Basin, Australia) ${ }^{11}$ to high volatile $\mathrm{C}$ bituminous (Ctenis laxa: Early Jurassic of the Vomb Trough, southern Sweden) ${ }^{12}$. All samples of extant plants were collected in the Botanical garden at Lund University, Sweden.

\begin{tabular}{|c|c|c|c|}
\hline Species name & Locality & Age & $\begin{array}{l}\text { Age in } \\
\text { million } \\
\text { years (ca.) }\end{array}$ \\
\hline \multicolumn{4}{|l|}{ FOSSIL } \\
\hline Podocarpus alwyniae & Otago, New Zealand & Miocene $^{1}$ & $23-16$ \\
\hline Retrophyllum vulcanense & Otago, New Zealand & Miocene $^{1}$ & $23-16$ \\
\hline Agathis yallournensis & Gippsland Basin, Victoria, Australia & Miocene $^{2}$ & $23-16$ \\
\hline Araucaria haastii & Shag Point, New Zealand & Late Cretaceous ${ }^{3}$ & 70 \\
\hline Otozamites boolensis & Gippsland Basin, Victoria, Australia & Early Cretaceous ${ }^{4}$ & 130 \\
\hline Allocladus helgei & $\begin{array}{l}\text { Clarence-Moreton Basin, Queensland, } \\
\text { Australia }\end{array}$ & Early Jurassic $5,6,7$ & 180 \\
\hline Nilssonia brevis & Skåne, Sweden & Early Jurassic ${ }^{8}$ & 180 \\
\hline Ctenis laxa & Skåne, Sweden & Early Jurassic ${ }^{8}$ & 200 \\
\hline Czekanowskia nathorstii & Scoresby Sound, East Greenland & Earliest Jurassic ${ }^{9}$ & 200 \\
\hline Ginkgo minuta & Scoresby Sound, East Greenland & Latest Triassic ${ }^{9}$ & 205 \\
\hline Ginkgo obovatus & Scoresby Sound, East Greenland & Latest Triassic ${ }^{9}$ & 205 \\
\hline Pterophyllum schenkii & Scoresby Sound, East Greenland & Latest Triassic ${ }^{10}$ & 205 \\
\hline Ptilozamites nilssonii & Scoresby Sound, East Greenland & Latest Triassic ${ }^{10}$ & 205 \\
\hline
\end{tabular}

\section{MODERN}

Ginkgo biloba

Cycas zeylanica

Araucaria bidwillii

Araucaria cunninghamii

Araucaria heterophylla

Agathis robusta

Wollemia nobilis
Botanical garden, Lund, Sweden

Botanical garden, Lund, Sweden

Botanical garden, Lund, Sweden

Botanical garden, Lund, Sweden

Botanical garden, Lund, Sweden

Botanical garden, Lund, Sweden

Botanical garden, Lund, Sweden

$\begin{array}{ll}\text { Anthropocene } & 0 \\ \text { Anthropocene } & 0 \\ \text { Anthropocene } & 0 \\ \text { Anthropocene } & 0 \\ \text { Anthropocene } & 0 \\ \text { Anthropocene } & 0 \\ \text { Anthropocene } & 0\end{array}$




\section{Spectral analysis}

Assignments of the modern plant cuticle IR spectral bands to molecular signals follow Heredia-Guerrero et al. ${ }^{13}$ and Villena et al. ${ }^{14}$. Briefly, a broad band at $3700-3000 \mathrm{~cm}^{-1}$ is assigned to vibrations of a hydroxyl functional group. Sharp bands at 2960-2850 $\mathrm{cm}^{-1}$ are assigned to stretching vibrations of $\mathrm{CH}_{2}$ and $\mathrm{CH}_{3}$ functional groups in aliphatic material. A band at $1734 \mathrm{~cm}^{-1}$ is assigned to $\mathrm{C}=\mathrm{O}$ vibration in esters (cutin, lipids). Bands in the $1650-1500 \mathrm{~cm}^{-1}$ spectral region are due to cyclic (aromatic, phenolic) compounds in the plants' cuticles. Bands due to deformation vibrations of $\mathrm{CH}_{2}$ and $\mathrm{CH}_{3}$ appear in the $1490-1400 \mathrm{~cm}^{-1}$ spectral region. Bands in the $1200-970 \mathrm{~cm}^{-1}$ region are due to $\mathrm{CO}, \mathrm{C}-\mathrm{O}-\mathrm{C}, \delta(\mathrm{OH})$ vibrations in polysaccharides.

For the fossil samples, a broad band at $3700-3000 \mathrm{~cm}^{-1}$ is assigned to vibrations of a hydroxyl functional group. The relative intensity of this band in spectra of fossil samples is considerably lower suggesting markedly lower water content. Sharp bands at $2960-2850 \mathrm{~cm}^{-1}$ are assigned to stretching vibrations of $\mathrm{CH}_{2}$ and $\mathrm{CH}_{3}$ functional groups in aliphatic material. A band at $1734 \mathrm{~cm}^{-1}$ is assigned to $\mathrm{C}=\mathrm{O}$ vibration in esters. The relative intensity of this band in spectra of the fossil samples is diminished or absent in comparison to the spectra of the modern plants. Instead, a band at $1710 \mathrm{~cm}^{-1}$, assigned to carboxylic acid/ketone $\mathrm{C}=\mathrm{O}$ vibration appears. Bands in the 1650-1500 $\mathrm{cm}^{-1}$ spectral region are due to cyclic (aromatic, phenolic) compounds in the plants' cuticles. The relative intensities of these bands are much higher in the spectra of the fossils. This suggests stability of the compounds containing these functional groups. Bands due to deformation vibrations of $\mathrm{CH}_{2}$ and $\mathrm{CH}_{3}$ appear in the 1490-1400 $\mathrm{cm}^{-1}$ spectral region. Spectral bands, assigned to vibrations of polysaccharides in the spectra of the modern samples, are absent from the spectra of the fossils. A spectral band at approximately $1250 \mathrm{~cm}^{-1}$ could be assigned to $\mathrm{OH}$ deformation of phenolic compounds, whereas broad bands at 1174 and $1034 \mathrm{~cm}^{-1}$ are due to $\mathrm{C}-\mathrm{O}-\mathrm{C}$ vibrations (ester). Broad spectral bands at 1250, 1174 and $1035 \mathrm{~cm}^{-1}$ remain unassigned; $\mathrm{C}-\mathrm{O}$ vibrations are normally present in this spectral region. Spectral bands at 3620, 3653, 3670, 3698, 1115, 1034, 1008 and $913 \mathrm{~cm}^{-1}$ (shoulder at 939 $\mathrm{cm}^{-1}$ ) are assigned to the mineral kaolinite. 


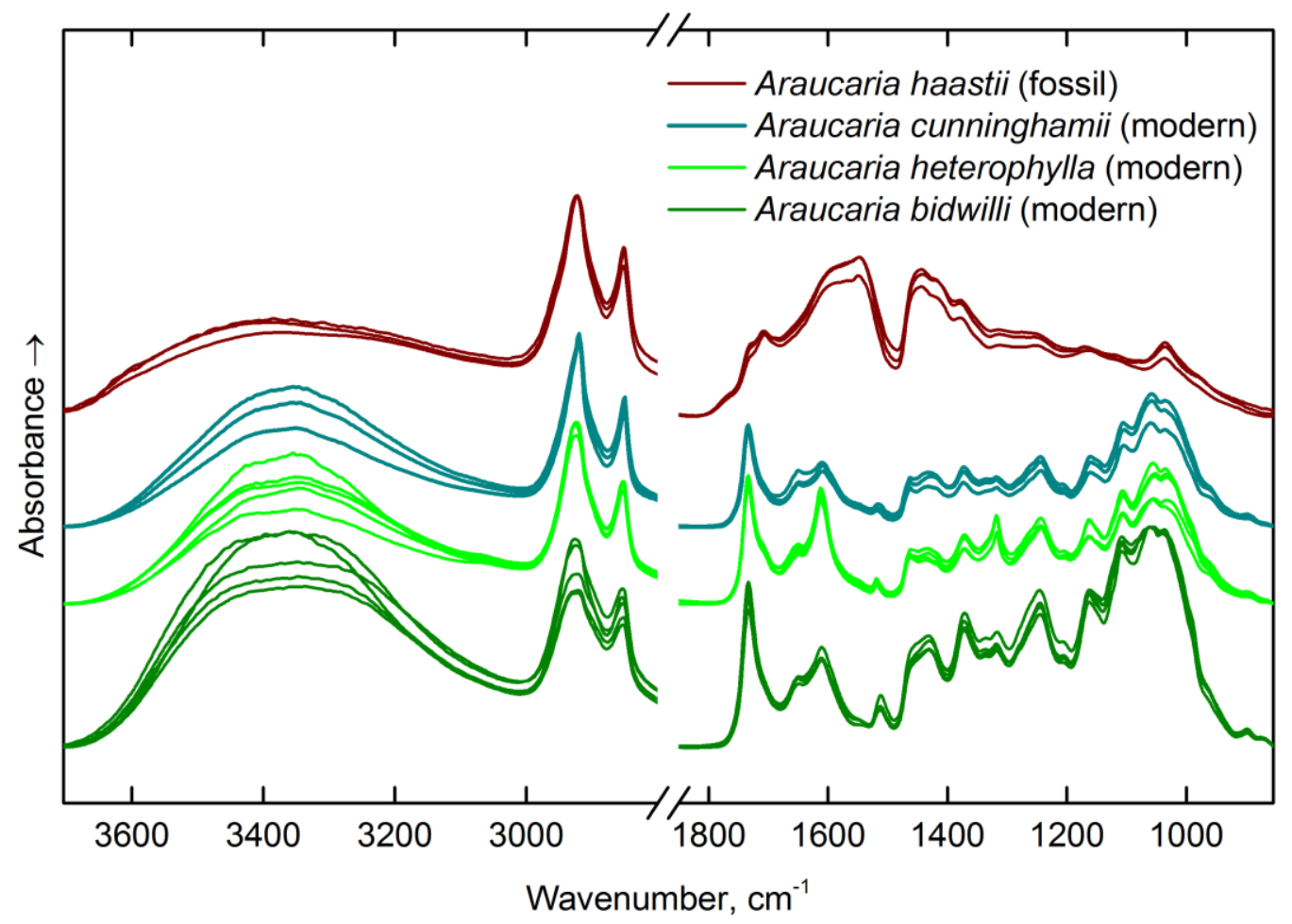

Supplementary Figure 1. IR absorption spectra of modern (Araucaria bidwilli, Araucaria heterophylla and Araucaria cunninghamii) and fossil (Araucaria haastii) araucariacean conifer cuticles. Note the diminished content of water $\left(3700-3000 \mathrm{~cm}^{-1}\right)$ and absence of spectral bands assigned to polysaccharides in the spectral region 1200$970 \mathrm{~cm}^{-1}$ in the spectra of fossil samples. The ester band at $1734 \mathrm{~cm}^{-1}$ in the spectra of the modern plants is replaced by carboxylic acid/ketone band at $1710 \mathrm{~cm}^{-1}$ in the spectra of the fossils.

\section{PCA analysis}

Principal Component Analysis (PCA) was used as an additional tool to identify relations between the data (Supplementary Fig. 6-8). PCA generates new variablesprincipal components (PCs) - which are linear combinations of the original dataset. Each PC represents variance of the data and, therefore, can be used for highlighting differences between the spectra. PCA was performed using the Matlab function princomp, which employs a covariance matrix to calculate the PCs. PC score plots were compiled from the first three components (accounting for approximately $95 \%$ of variance depending on the sample set) in order to observe the relationships between the sample groups. The PCA analysis yields similar results to the HCA and supports the conclusions of this work. It should be noted, however, that the PCA does not group the data, but rather shows the relationship between the data points. Nevertheless, PCA score plots (PC1 vs. PC2 and PC1 vs. PC3) reveal that spectra of each plant - modern or fossil - form discrete clusters. 

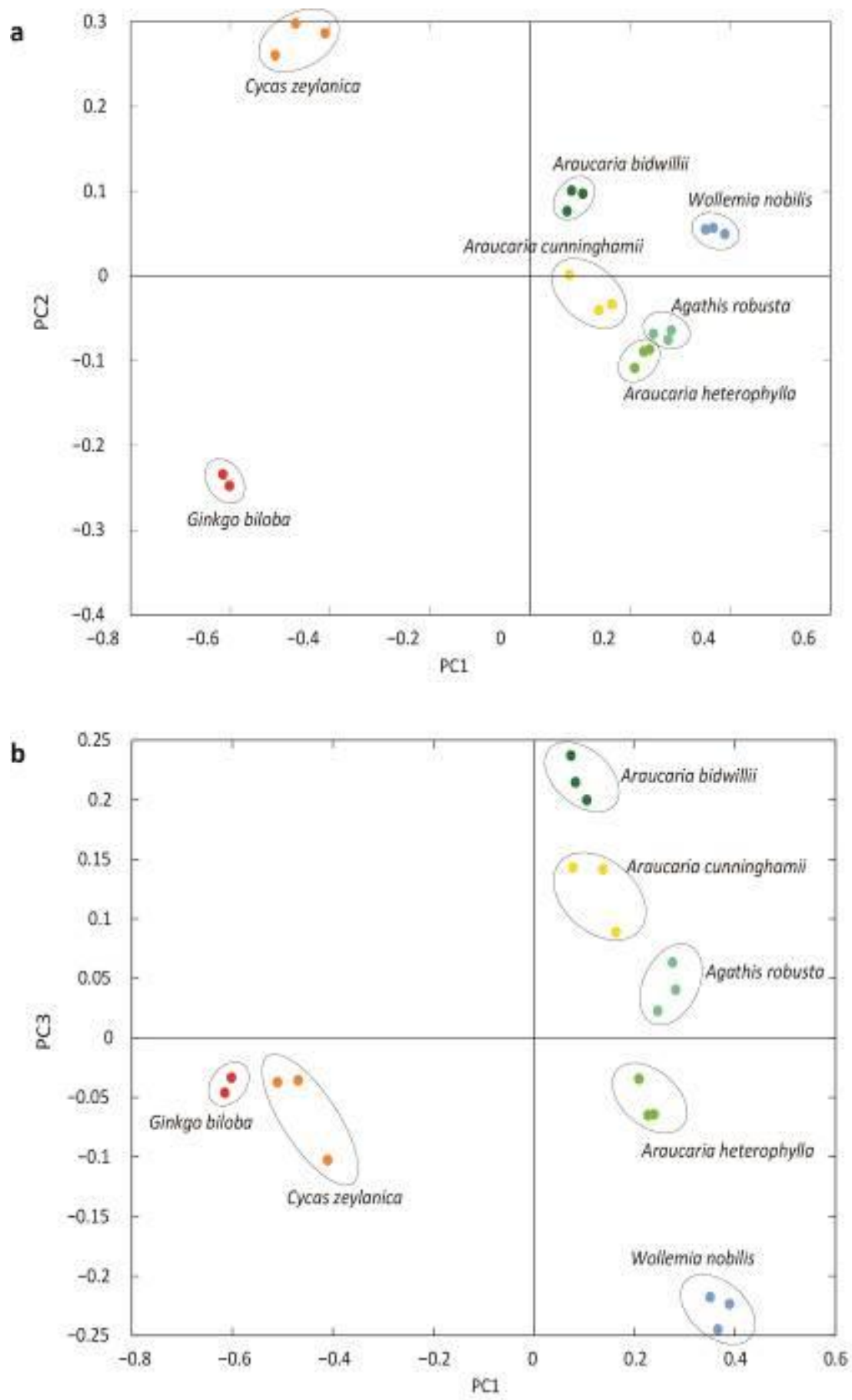

\section{Supplementary Figure 2. PCA score plots based on IR absorption spectra of the cuticles of extant gymnosperms.}

Two major groups of data points can be separated: (I) cycads and ginkgos and (II) Araucariaceae. Although the cycads and ginkgoaleans plot close to each other in one dimension (b), they are relatively remote in the other (a) indicating substantial divergence between these subgroups. Araucariaceae are always clustered together. 

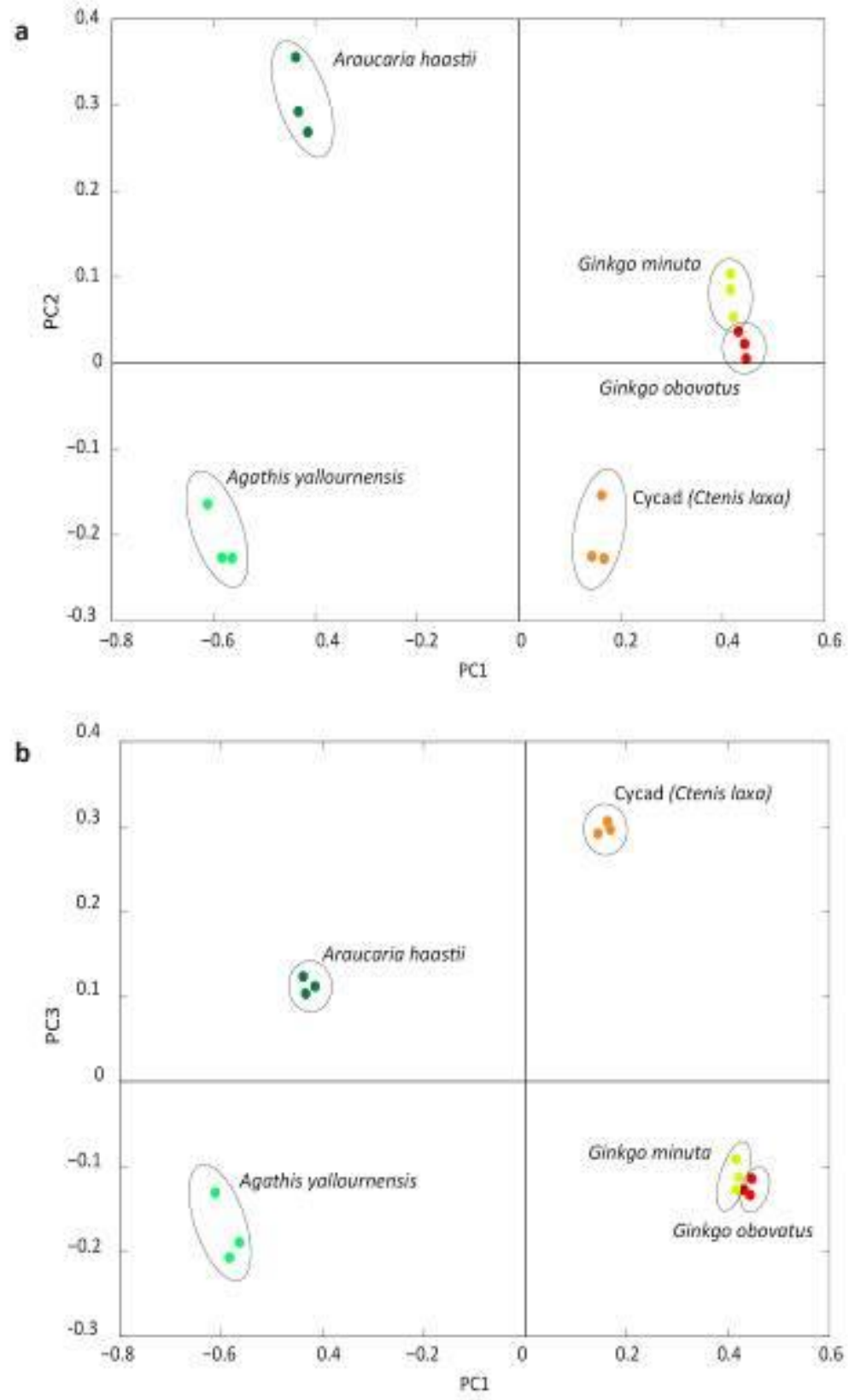

\section{Supplementary Figure 3.}

PCA score plots based on IR absorption spectra of the cuticles of fossil gymnosperms related to the extant taxa analysed in Supplementary Figure 2.

As for the modern plants, the same two major groups of data points can be identified amongst the fossils: (I) cycads and ginkgos and (II) Araucariaceae. Although the cycads and ginkgoaleans plot close to each other in one dimension (a), they are, just as in the modern counterparts, relatively remote in the other (b) indicating substantial divergence between these subgroups. 
a
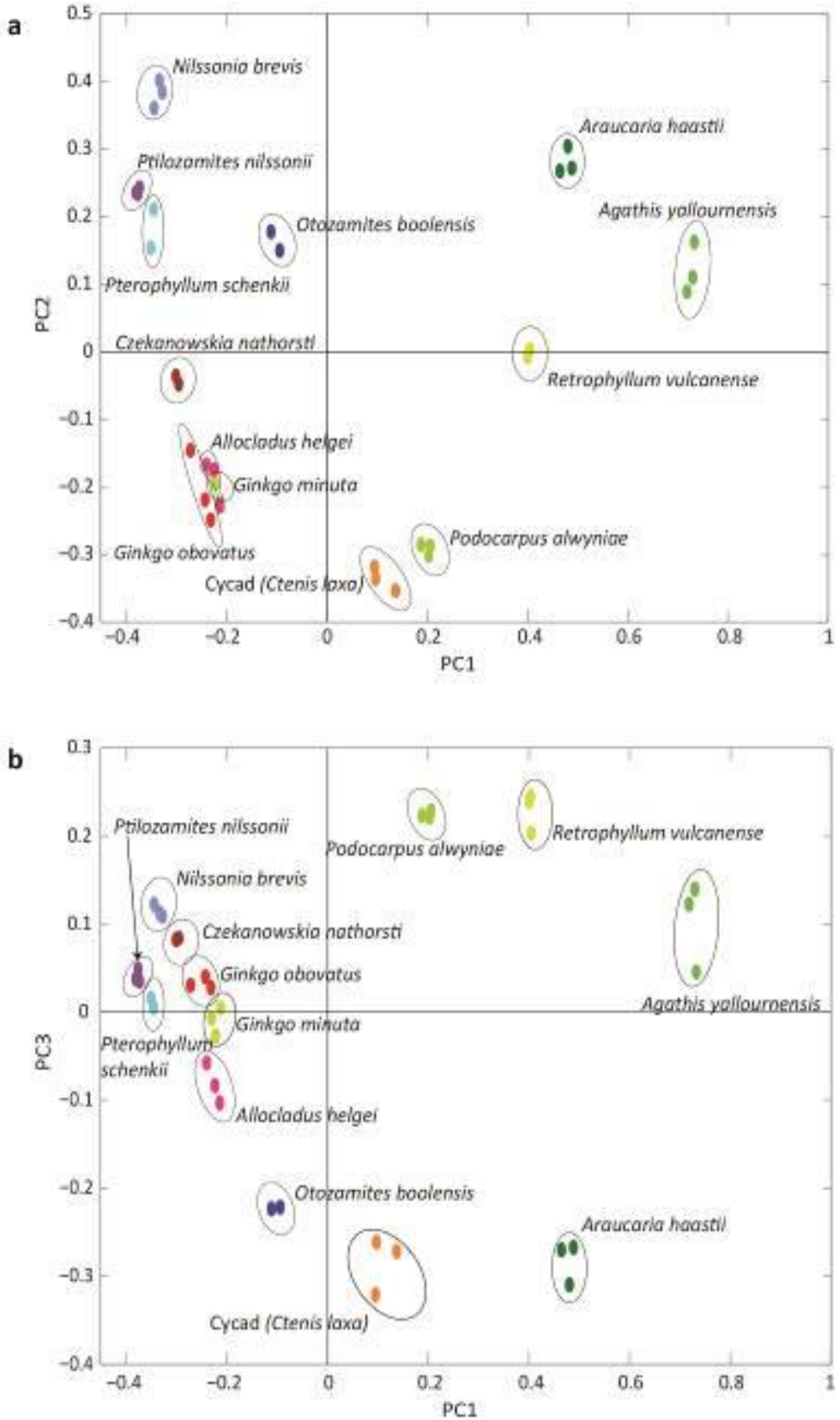

\section{Supplementary Figure 4.}

PCA score plots based on IR absorption spectra of the cuticles of 13 fossil gymnosperms. Despite more taxon sampling, the conifers (Araucariaceae and Podocarpaceae) group in a discrete sector of the ordination space $(\mathbf{a}, \mathbf{b})$. The extinct Nilssoniales and Ptilozamites are more closely allied with Bennettitales rather than with Cycadales. A similar close relationship is evident between Ginkgoales and the extinct Leptostrobales. 


\section{Supplementary References}

1. Pole, M. Miocene conifers from the Manuherikia Group, New Zealand. J. Roy. Soc. NZ. 27, 355-370 (1997).

2. Cookson, I. C. \& Duigan, S. L. Tertiary Araucariaceae from south-eastern Australia, with notes on living species. Aust. J. Sci. Res. 4, 415-449. (1951).

3. Bose, M. N. Araucaria haastii Ettingshausen from Shag Point, New Zealand. Palaeobotanist 22, 76-880. (1975).

4. McLoughlin, S., Tosolini, A.-M., Nagalingum, N. \& Drinnan, A. N. The Early Cretaceous (Neocomian) flora and fauna of the lower Strzelecki Group, Gippsland Basin, Victoria, Australia. Mem. Assoc. Australas. Palaeontols. 26, 1-144 (2002).

5. Jansson, I.-M., McLoughlin, S., Vajda, V. \& Pole, M. An Early Jurassic flora from the Clarence-Moreton Basin, Australia. Rev. Palaeobot. Palynol. 150, 5-21 (2008).

6. Jansson, I.-M., McLoughlin, S. \& Vajda, V. Early Jurassic annelid cocoons from eastern Australia. Alcheringa 32, 285-296 (2008).

7. Steinthorsdottir, M. \& Vajda, V. Early Jurassic (late Pliensbachian) $\mathrm{CO}_{2}$ concentrations based on stomatal analysis of fossil conifer leaves from eastern Australia. Gondwana Res. 27, 932-939 (2015).

8. Lundblad, A. B. Studies in the Rhaeto-Liassic floras of Sweden. I. Pteridophyta, Pteridospermae and Cycadophyta from the mining district of NW Scania. Kungl. Sv. Vetensk. Handl., Fourth Series 1, 1-82 (1950).

9. Harris, T. M. The fossil flora of Scoresby Sound East Greenland. Part 4: Ginkgoales, coniferales, lycopodiales and isolated fructifications. Medd. Grønland 112(1), 1-176 (1935)

10. Harris, T. M. The fossil Flora of Scoresby Sound East Greenland, Part 3: Caytoniales and Bennittitales. Medd. Grønland 85(5), 1-333 (1932).

11. Holdgate, G. R. Geological processes that control lateral and vertical variability in coal seam moisture contents-Latrobe Valley (Gippsland Basin) Australia. Int. J. Coal Geol. 63, 130-155 (2005).

12. Petersen, H. I., Nielsen, L. H., Bidstrup, T. \& Thomsen, E. Burial depth and post-Early Cretaceous uplift of Lower-Middle Jurassic strata in the Fennoscandian Border Zone based on organic maturity. Jurassic Denmark Greenland. Geol. Surv. Denmark Greenl. Bull. 1, 611-630 (2003).

13. Heredia-Guerrero, J. A. et al. Infrared and Raman spectroscopic features of plant cuticles: a review. Front. Plant Sci. 5(305), 1-14 (2014).

14. Villena, J. F., Dominguez, E. \& Heredia, A. Monitoring biopolymers present in plant cuticles by FT-IR spectroscopy. J. Plant Physiol. 156, 419-422 (2000). 